\title{
Comments on "A Neurobiological Model for Near-Death Experiences"
}

\author{
Richard S. Blacher, M.D. \\ Tufts University
}

It has been an act of courage for the Journal to have published this paper by Juan C. Saavedra-Aguilar and Juan S. Gómez-Jeria, since so many of its readers approach the issue of near-death experiences (NDEs) from such a different, spiritual point of view. This review by Saavedra-Aguilar and Gómez-Jeria clearly suggests that NDEs have nothing to do with either death or experiences, if "experiences" means those outside the nervous system.

The term NDE implies, for some of us, that the person was in danger of dying. A bullet missing someone's head by an inch is just as much a near-death as a cardiac event, yet the near-death phenomena are not elicited by the bullet. For other people, the term NDE implies that a person has died and returned to life. The latter is essentially a legitimate religious or spiritual point of view, but not really subject to scientific discussion. Although I would focus more on the aspects of depersonalization (Blacher, 1983), the neurological approach presented in this paper is consonant with my psychological views, since I cannot conceptualize psychic activity as separate from brain function.

While the authors emphasize that temporal lobe phenomena and near-death phenomena are very similar, it may be too narrow a focus to relate all near-death phenomena to the temporal lobe, since we are not dealing with demonstrable lesions of that lobe but rather with more general brain reactions. Perhaps an even better parallel might be the psychological reaction of depersonalization (Arlow, 1966) combined

Dr. Blacher is Professor of Psychiatry and Lecturer in Surgery at the Tufts University School of Medicine. Requests for reprints should be addressed to Dr. Blacher at the TuftsNew England Medical Center Hospital, 171 Harrison Avenue, Boston, MA 02111. 
with the elements of dreaming (Blacher, 1983). Often in a setting of some hypoxia, such as cardiac events and ether anesthesia, there is a regressive pull to a dreamlike state, similar to that seen in nightmares, which are both terrifying and real. However, the NDE is felt as reassuring and real, with the subjects feeling themselves separate from the endangered sick person being resuscitated. They feel, "That person can die, but not I. I will live forever."

Saavedra-Aguilar and Gómez-Jeria have outlined neurological mechanisms for near-death phenomena. Unfortunately, the pathways cannot explain the content of the experiences; that is the domain of psychology. But this review is a down-to-earth essay that provides an important basis for understanding an important aspect of these phenomena.

\section{References}

Arlow, J. A. (1966). Depersonalization and derealization. Pp. 456-478 in Loewenstein, R. M., Newman, L. M., Schur, M., and Solnit, A. J. (eds.), Psychoanalysis: A general psychology. New York, NY: International Universities Press.

Blacher, R. S. (1983). Death, resurrection, and rebirth: Observations in cardiac surgery. Psychoanalytic Quarterly, 52, 56-72. 